\title{
Functional Maturation of the Macaque's Lateral Geniculate Nucleus
}

\author{
J. Anthony Movshon, Lynne Kiorpes, Michael J. Hawken, and James R. Cavanaugh \\ Center for Neural Science, New York University, New York, New York 10003
}

\begin{abstract}
Vision in infant primates is poor, but it is not known which structures in the eye or brain set the main limits to its development. We studied the visual response properties of 348 neurons recorded in the lateral geniculate nucleus (LGN) of macaque monkeys aged 1 week to adult. We measured spatial and temporal frequency tuning curves and contrast responses with drifting achromatic sinusoidal gratings. Even in animals as young as 1 week, the main visual response properties of neurons in the magnocellular $(\mathrm{M})$ and parvocellular $(\mathrm{P})$ divisions of the LGN were qualitatively normal, including the spatial organization of receptive fields and the characteristic response properties that differentiate M- and P-cells. At 1 and 4 weeks, spatial and temporal resolution were less than one-half of adult values, whereas contrast gain and peak response rates for optimal stimuli were about two-thirds of adult values. Adult levels were reached by 24 weeks. Analysis of correlations between S-potentials representing retinal inputs and LGN cells suggested that the LGN follows retinal input as faithfully in infants as in adults, implicating retinal development as the main driving force in LGN development. Comparisons with previously published psychophysical data and ideal observer models suggest that the relatively modest changes in LGN responses during maturation impose no significant limits on visual performance. In contrast to previous studies, we conclude that these limits are set by neural development in the visual cortex, not in or peripheral to the LGN.
\end{abstract}

Key words: macaque monkey; lateral geniculate nucleus; development; vision; spatial; temporal

\section{Introduction}

Vision is immature in primate newborns. Acuity and contrast sensitivity improve 10- to 30-fold over the course of maturation. Behavioral studies in animals and humans show a steady progression of development over the first 3-4 months in cat (Mitchell et al., 1976), 6-9 months in macaque monkey (Boothe et al., 1988; Kiorpes, 1992), and 3-6 years in humans (Mayer and Dobson, 1982; Ellemberg et al., 1999). The neural limitations on this process have not been established (Kiorpes and Movshon, 2004). It is widely assumed that the retinal mosaic sets the primary limit on acuity in adult primates (Wässle and Boycott, 1991). However, morphological analyses of the development of photoreceptors show that the packing density of cones in the central fovea can support resolution far higher than the infant can achieve (Brown et al., 1987; Banks and Bennett, 1988; Kiorpes et al., 2003). Furthermore, although cone photoreceptors have immature morphology that limits their sensitivity to light (Hendrickson, 1992), ideal observer analyses show that these immaturities do not ac-

\footnotetext{
Received June 15, 2004; revised Jan. 13, 2005; accepted Jan. 27, 2005.

This work was supported by National Institutes of Health Project Grants EY02017 to J.A.M. and EY05864 to L.K., Core Grant EY13079 to New York University, and Grant RR00166 to Washington National Primate Research Center, and by an investigatorship to J.A.M. from the Howard Hughes Medical Institute. We are grateful to Larry O'Keefe, Ann Skoczenski, and Chao Tang for their help with data collection, to Wyeth Bair for performing the cross-correlation analysis, and to Suzanne Fenstemaker for histological assistance.

Correspondence should be addressed to Dr. J. Anthony Movshon, Center for Neural Science, New York University, 4 Washington Place, Room 809, New York, NY 10003. E-mail: movshon@nyu.edu.

J. R. Cavanaugh's present address: Laboratory for Sensorimotor Research, National Eye Institute, National Institutes of Health, Bethesda, MD 20892.

DOI:10.1523/JNEUROSCI.2356-04.2005

Copyright $\odot 2005$ Society for Neuroscience $\quad$ 0270-6474/05/252712-11\$15.00/0
}

count for the behaviorally measured sensitivity of infants (Banks and Crowell, 1993; Brown, 1993; Kiorpes et al., 2003) (but see Wilson, 1988, 1993). Thus, important neural limitations to acuity and contrast sensitivity in infants must lie central to the photoreceptors.

No studies have been published on the development of retinal ganglion cell receptive fields in primates. In kittens, center-surround organization is present near the time of eye opening: the response of the center mechanism is adult-like but surround responses are weak (Rusoff and Dubin, 1977). The lateral geniculate nucleus (LGN) receives information from all of the major classes of ganglion cells and provides the afferent input to the primary visual cortex. Two previous studies of development in primate LGN suggest a correlation between acuity and contrast sensitivity development, and the maturation of receptive field properties in LGN neurons (Blakemore and Vital-Durand, 1986; Hawken et al., 1997). Blakemore and Vital-Durand (1986) found neurons in infants to be visually responsive, but sluggish, weak, and with a tendency to fatigue. The resolution of LGN cells at different ages, assessed qualitatively, was reasonably well matched to behaviorally measured acuity up to age $\sim 3$ months. There was more maturation of the acuity of neurons representing the central visual field than of those representing more peripheral retina. Behavioral data from infant macaques show a similar pattern of acuity across the visual field, with the greatest maturation of acuity within the central visual field (Kiorpes and Kiper, 1996), although the time course is more prolonged. Finally, the envelope of contrast sensitivity of LGN neurons representing the center of gaze develops similarly to behaviorally measured contrast sensitivity of infant monkeys, showing adult-like sensitivity by $\sim 8$ 
months (Boothe et al., 1988; Kiorpes and Kiper, 1996; Hawken et al., 1997). Hawken et al. (1997) also found a difference in temporal responsiveness between LGN neurons in neonates and adults. We know of no behavioral data on the development of temporal sensitivity in monkeys.

These data suggest that properties of neurons in the LGN may represent an important neural limitation on the development of basic spatial and temporal vision. However, previous studies were rather limited. Blakemore and Vital-Durand (1986) concentrated on a qualitative analysis of spatial resolution, whereas Hawken et al. (1997) concentrated on magnocellular (M)-cells. Because it is critical to know precisely what limits to visual development are established at or before the level of the LGN, we conducted a systematic quantitative examination of the maturation of visual signaling of spatial, temporal, and contrast information. In contrast to previous studies, we found the responses of infant LGN cells to be quite mature in most respects. The spatial and temporal resolution and contrast responses of LGN cells of both main types improve only modestly during early development. Quantitative comparisons with behavioral data and with an ideal observer indicate that the main limitations on visual performance in infant macaques lie central to the LGN.

\section{Materials and Methods}

We recorded from nine visually normal pig-tailed macaques, Macaca nemestrina. Two were adults aged 2 and 7 years, three were juveniles $(6,7$, and 10 months), two were 4 weeks of age ( 22 and $32 \mathrm{~d}$ ), and two were 1 week of age ( 8 and $9 \mathrm{~d}$ ). To minimize the variability of data from very young animals, infants were selected for early study on the basis of having birth weights and dentition near the middle of the normal range. All of the animals were confirmed to have normal vision before recording. For the infants, we measured grating acuity using preferential looking techniques, and for the older animals, we measured full contrast sensitivity functions with operant methods. Behavioral data from some of these animals have been reported previously (Kiorpes and Movshon, 1998). We made quantitative measurements of the response properties of 111 cells [90 parvocellular (P)-cells and $21 \mathrm{M}$-cells] from the 1-week-old animals, 108 cells ( $80 \mathrm{P}$-cells and $28 \mathrm{M}$-cells) from the 4 -week-old animals, and 129 cells ( 95 P-cells and $34 \mathrm{M}$-cells) from the adult animals. In the 1 week data set, all of the M-cells were recorded from a single monkey; otherwise, cells of both types were recorded from each animal in each group.

Surgical preparation and maintenance. Animals were premedicated with intramuscular injections of atropine $(0.04 \mu \mathrm{g} / \mathrm{kg})$, and acepromazine maleate $(0.5-1.0 \mathrm{mg} / \mathrm{kg})$. Anesthesia was induced with an intramuscular injection of ketamine $\mathrm{HCl}$ (Ketaset; $5-40 \mathrm{mg} / \mathrm{kg}$ ) and maintained during surgery with halothane in $2 \% \mathrm{CO}_{2}$ balanced with oxygen or room air. We inserted cannulas in the saphenous veins for paralytic and anesthetic infusions, and into the trachea for artificial ventilation. The animal was then placed in a stereotaxic frame. Throughout the experiment, anesthesia was maintained with an intravenous infusion of sufentanil citrate (Sufenta; $4-10 \mu \mathrm{g} \cdot \mathrm{kg}^{-1} \cdot \mathrm{h}^{-1}$ ). We ventilated the animal with room air or with a mixture of $\mathrm{N}_{2} \mathrm{O}$ and $\mathrm{O}_{2}$ (up to $50 \% \mathrm{~N}_{2} \mathrm{O}$ ). To minimize eye movement, we induced paralysis with vecuronium bromide (Norcuron; $0.1 \mathrm{mg} \cdot \mathrm{kg}^{-1} \cdot \mathrm{h}^{-1}$ ). Norcuron and Sufenta were delivered in Normosol solution with $2.5 \%$ dextrose $\left(5 \mathrm{ml} \cdot \mathrm{kg}^{-1} \cdot \mathrm{h}^{-1}\right)$.

We administered atropine sulfate $(1 \%)$ drops to each eye to dilate the pupils and paralyze accommodation. Gas-permeable $+2 \mathrm{D}$ contact lenses were placed in each eye to protect the corneas. The contact lenses were removed for cleaning each day. We estimated refractive error by direct ophthalmoscopy and refined the estimate by optimizing the response of visual units. Supplementary spectacle lenses were used to make the retinas conjugate with a computer screen $172 \mathrm{~cm}$ distant.

For the older animals, we fixed the head in a stereotaxic frame. For 1and 4-week-old infants, we reinforced the skull-which is quite flexible at these ages - with a dental acrylic cap, into which a post was cemented; the animal's head was suspended by attaching this post to the stereotaxic frame. We made a small craniotomy at a location determined from skull landmarks and/or stereotaxic coordinates to overlie the LGN, and made a small incision in the underlying dura. A hydraulic microdrive advanced a tungsten-in-glass microelectrode (Merrill and Ainsworth, 1972) into the LGN. We recorded action potentials from single LGN neurons and occasionally recorded correlated S-potentials, which reflect the activity of afferent retinal ganglion cells fibers (Kaplan and Shapley, 1984). Electrical potentials were conventionally amplified and displayed and played over an audiomonitor. The time of occurrence of each impulse was stored by the computer with a precision of $0.25 \mathrm{~ms}$.

Throughout the recording session, we closely monitored the monkey's physiological state, to ensure the proper level of anesthesia. We monitored electrocardiogram (EKG), EEG, heart rate, blood pressure, expired $\mathrm{CO}_{2}$, core temperature, and urine flow. We used the EKG, EEG, and heart rate to monitor the monkey's state of arousal, and adjusted the infusion rate of the sufentanil when needed to ensure a proper level of anesthesia. Expired peak $\mathrm{CO}_{2}$ was maintained near $4 \%$ by adjusting respirator stroke volume. Body temperature was maintained at $\sim 36.5^{\circ} \mathrm{C}$ with a thermostatically controlled heating pad. We gave the monkey daily intramuscular injections of Bicillin (300,000 U), a broad-spectrum antibiotic, and dexamethasone ( $1 \mathrm{mg} / \mathrm{kg})$ to prevent cerebral edema, as well as limb massages to prevent pooling of blood in the great veins.

Visual stimuli and neuronal characterization. We mapped the projection of the fovea of each eye on a tangent screen using a reversible ophthalmoscope. Because the fovea is immature and difficult to visualize in young animals, we also plotted the optic disk to confirm our location of the fovea in these cases. For each isolated unit, we determined eye preference, and we mapped the receptive field of the unit, noting its position with respect to the fovea. All of the receptive fields were within $16^{\circ}$ of visual angle from the fovea, and most $(94 \%,<1$ week; $91 \%, 4$ weeks; $80 \%,>24$ weeks) were within $7^{\circ}$. We then characterized the properties of the unit by ear, noting responsiveness to chromatic and achromatic stimuli and spatial organization as on- or off-center.

We then centered the receptive field of the preferred eye of the unit on the face of a Nanao T560i monitor placed at a viewing distance of $172 \mathrm{~cm}$ for quantitative evaluation of the properties of the unit; the other eye was covered. We used a personal computer with a Truevision AT Vista video board and a suitable laboratory interface to present visual stimuli and collect responses. The frame rate of our display was $107 \mathrm{~Hz}$, and the space- and time-averaged luminance was $33 \mathrm{~cd} / \mathrm{m}^{2}$. For all of the experiments reported here, we used drifting achromatic vertical or horizontal sinusoidal gratings. We varied spatial and temporal parameters of the gratings to measure tuning properties of each cell, and then measured the contrast response properties of the cell.

Each experiment consisted of between three and eight blocks of randomly interleaved stimuli, including blank trials that allowed us to measure the spontaneous activity of the cell. In the spatial tuning experiments, we used sinusoidal gratings drifting at a fixed temporal frequency, usually $6.7 \mathrm{~Hz}$. We presented seven spatial frequencies in octave steps from 0.16 to $10 \mathrm{c} / \mathrm{deg}$, as well as a uniform temporally modulating field (zero spatial frequency) to obtain a complete spatial frequency tuning function. We measured temporal frequency tuning with drifting gratings of the preferred spatial frequency of the cell. We presented eight different temporal frequencies, ranging from 0.4 to $27 \mathrm{~Hz}$, to characterize the temporal tuning function. To measure contrast responses, we presented gratings of the optimal spatial frequency, drifting at $6.7 \mathrm{~Hz}$ (unless a lower frequency was required to drive the cell), at eight different luminance contrasts. We often used a lower range of contrasts for M-cells than for P-cells, but the range was adjusted as needed to accommodate the sensitivity of the individual units.

Data analysis. Most analysis followed that detailed by Levitt et al. (2001). All of the responses were measured by the amplitude and, where appropriate, the phase of the response component modulated at the temporal frequency of the stimulus. We fit the spatial frequency tuning data with a difference of Gaussians (DoG) as follows:

$$
R\left(\omega_{x}\right)=k\left[\left(\exp -\left(\omega_{x} / f_{c}\right)^{2}\right)-k_{s}\left(\exp -\left(\omega_{x} / f_{s}\right)^{2}\right)\right],
$$

where $\omega_{x}$ is the spatial frequency, $k$ is a scaling constant, $f_{c}$ is the characteristic spatial frequency of the receptive field center Gaussian (the fre- 
quency at which its response contribution falls to $1 / e$ of maximum), $k_{s}$ is the integrated weight of the surround relative to the center, and $f_{s}$ is the characteristic spatial frequency of the surround Gaussian. Following Enroth-Cugell and Robson (1966) and Linsenmeier et al. (1982), we take $f_{c}$ as a measure of the spatial resolution of the receptive field, as the frequency at which the strength of the center mechanism has fallen to $1 / e$ of its maximum. $1 / \pi f_{c}$ is a standard measure of receptive field center size.

We fit temporal frequency tuning curves with a function of the following form:

$$
R\left(\omega_{t}\right)=\frac{k \cdot \exp \left[\left(-\omega_{t} / f_{c}\right)^{2}\right]}{\left[1+\left(f_{h} / \omega_{t}\right)^{\beta}\right]},
$$

where $\omega_{t}$ is the temporal frequency, $k$ is a scaling constant, $f_{c}$ is the characteristic temporal frequency, $f_{h}$ sets the corner frequency of the low-frequency limb of the function, and $\beta$ sets the slope of the lowfrequency limb. By analogy with spatial frequency tuning, we use $f_{c}$ to measure temporal resolution, as the frequency at which the response of the "core" of the temporal impulse function falls to $1 / e$ of its maximum. In addition, using a weighted least-squares method (Reid et al., 1992), we fit the phase of the modulated response as a function of temporal frequency with a line whose slope gives an estimate of the steady-state response delay (Levitt et al., 2001), here termed "integration time" (Reid et al., 1992).

We fit contrast response data with the function introduced by EnrothCugell and Robson (1966):

$$
R(C)=b+k \cdot \log \left(1+\frac{C}{C_{0}}\right)
$$

with corrections for response phase variability that were described in detail by Levitt et al. (2001). Here, $C$ is the stimulus contrast, $k$ is a scaling constant, $b$ is a baseline offset $\leq 0$, and $C_{0}$ is a saturation constant representing the contrast at which logarithmic contrast saturation begins. When $b$ is 0 , as is the case for almost all of the cells in adult LGN, the initial slope of this function, $k / C_{0}$, is the "responsivity" or "contrast gain." As detailed below, for neurons from infant monkeys that lacked spontaneous activity, $b$ assumed negative values. In that case, responsivity was taken as the slope of the function at the point at which $R(C)$ first exceeded 0 . In addition, to measure the phase shift in the response as a function of contrast (Shapley and Victor, 1978), we used a weighted least-squares method to fit a line to the relationship between phase and response amplitude at each test contrast:

$$
\phi(C)=\phi_{0}+p \cdot A(C),
$$

where $\phi_{0}$ is a constant, $p$ is the slope, and $\phi(C)$ and $A(C)$ are the phase and amplitude of response at contrast $C$. We took the magnitude of the fitted phase shift divided by the maximum test contrast to compute phase shift per unit contrast, and then divided this by the stimulus temporal frequency to give $\tau$, the normalized phase shift value in milliseconds as follows:

$$
\tau=p / C_{\max } / \omega_{t}
$$

Neuroanatomical methods. During recording, we made electrolytic lesions at points of interest along the microelectrode track by passing current through the electrode tip (1-2 $\mu \mathrm{A}$ for $2-5 \mathrm{~s}$; tip negative). At the conclusion of the experiment, the animal was killed by an overdose of barbiturate and perfused transcardially with heparinized saline, followed by $4 \%$ paraformaldahyde. The brain was removed and the tissue block containing the LGN was sunk in $30 \%$ sucrose in PBS. Coronal sections were cut at $40 \mu \mathrm{m}$ on a freezing microtome. The sections were stained for Nissl substance with cresyl violet. Electrode tracks were recovered, and recording sites were verified. The combination of physiological data on shifts in eye preference of recorded activity with the histological reconstructions allowed us unambiguously to assign each recorded unit to a particular LGN layer. In addition, reconstructed maps for each layer of the LGN from each individual infant were projected onto established maps of LGN topography (Malpeli and Baker, 1975; Malpeli et al., 1996) to verify and if necessary correct measured receptive field locations.

\section{Results}

Qualitatively, the organization of the LGN and the properties of its neurons were adult-like in all of the animals of all ages. All of the cells responded reliably to suitable luminance and chromatic targets, and were organized into layers both by eye preference and by response pattern. Because there are no accepted visual response criteria by which one can distinguish the "K cells" that are found in or near the interlaminar zones of the macaque LGN (Hendry and Reid, 2000), we compared the properties of cells near laminar borders and with cells near the centers of the laminas. Finding no consistent differences related to position within the layers, we simply classified our cells anatomically as $\mathrm{M}$ or $\mathrm{P}$ based on the layer in which they were recorded.

The visuotopic organization of the LGN and the ease with which responsive units could be isolated seemed identical in adults and infants. The most immediately noticeable difference between recordings in infants and adults was that spontaneous activity was much lower in infants. Mean spontaneous rates were $0.8 \mathrm{impulses} / \mathrm{s}$ (ips) in 1 week olds and 1.6 ips in 4 week olds, compared with 5.2 ips in adults. About one-third of the cells in young infants had spontaneous rates that were effectively $0(<0.2$ ips); such cells were very rare in adults. Visually evoked firing in infants, however, was generally robust and seemed only slightly less vigorous than in adults. It has been reported that the peak firing rate of neurons in the primate LGN is relatively low in young animals and that cells fatigue easily and are generally sluggish (Blakemore and Vital-Durand, 1986; Hawken et al., 1997), but we did not find infant neurons to be especially sluggish or prone to fatigue. Peak evoked firing rates for our cells grew only a little during development-the mean peak modulated rate in 1-week-old animals was 21.3 ips, growing to 26.2 ips at 4 weeks, and 28.4 ips in adults; the median rates followed a similar trend (14.3, 22.3, and 23.1 ips, respectively); M- and P-cells improved at similar rates. We also looked to see whether responses fell off significantly during a typical stimulus period $(2.5$ or $5 \mathrm{~s})$, and found little evidence for adaptation or fatigue in this time window in cells recorded at any age. It may be that the fatigability and low firing rates in previous studies were attributable in part to the use of barbiturate anesthetics, which in our experience depress neural activity more in young animals than do the opiates we used in this study.

\section{Spatial properties}

The spatial frequency tuning of four cells is illustrated in the left panels of Figure $1 a-d$. Each smooth curve drawn through the data points is the best fitting DoG function (see Materials and Methods). From this smooth curve, we obtained the characteristic spatial frequency of the center Gaussian, marked by a black arrow on each of the curves. Most individual cells in the two infant groups had tuning functions that were similar in shape to those of the adult, but the characteristic spatial frequency was, in general, lower in the younger animals. This change is exemplified by a comparison of the two example parvocellular neurons. The characteristic spatial frequency of the P-cell from a 1 week old was $2.3 \mathrm{c} / \mathrm{deg}$ (Fig. 1a, left), whereas that of the cell from the adult $\mathrm{P}$-cell was $8.2 \mathrm{c} / \mathrm{deg}$ ( $b$, left). There was a comparable difference in the characteristic spatial frequency of the magnocellular neurons (2.1 vs $3.9 \mathrm{c} / \mathrm{deg}$ ) (Fig. 1c,d). It should be noted that the characteristic spatial frequency is reciprocally related to the receptive field center radius. An increase in characteristic spatial frequency means a reduction in the receptive field center radius (EnrothCugell and Robson, 1966; Linsenmeier et al., 1982). Therefore, changes in characteristic spatial frequency reflect changes in the 

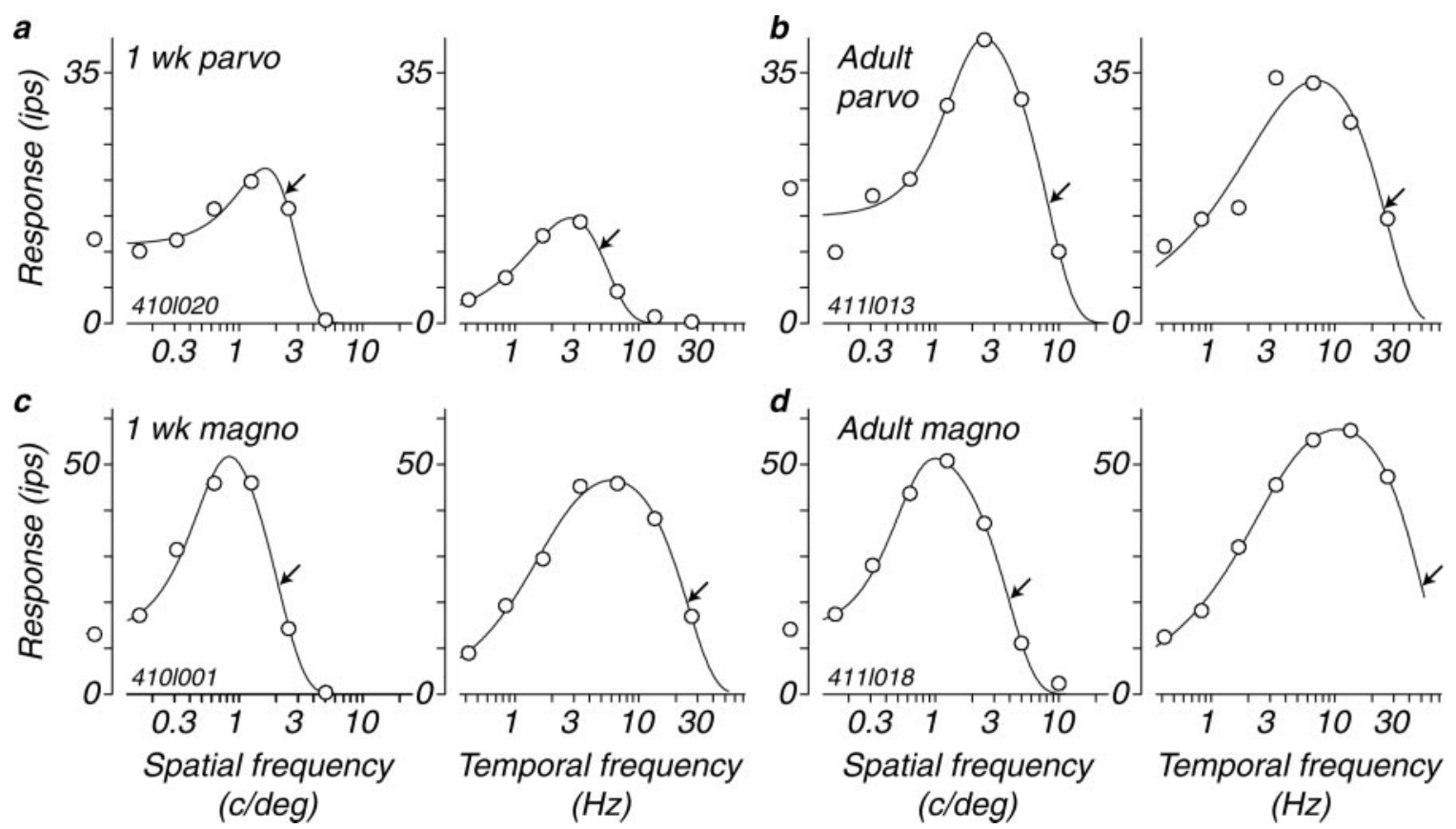

Figure 1. $\quad \boldsymbol{a}-\boldsymbol{d}$, Examples of spatial and temporal frequency tuning curves from four LGN M- and P-cells from 1-week-old infants and adults. Each point on the $y$-axis of all of the graphs shows the amplitude of the modulated response, the first harmonic. The smooth curves drawn through the points are the best-fitting functions that describe the data as described in Materials and Methods (Eqs. 1, 2). The arrows on each function show the values of the characteristic frequency that we use to describe the spatial and temporal resolution of the neurons. parvo, Parvocellular; magno, magnocellular.

size of the receptive field center. The characteristic spatial frequency and receptive field size, combined with the overall sensitivity, determine the spatial resolution of the cell. Another feature to note is that the cells illustrated in Figure 1 show attenuation of the response at lower spatial frequencies, indicating that the center-surround organization is already present in the first month postnatally. The distribution of surround strength relative to the center obtained from the best fitting DoG functions over the entire population of cells was similar for all three ages; the mean values of integrated relative surround strength ( $k_{s}$ from Eq. 1$)$ for cells from 1 week olds was 0.81 , from 4 week olds was 0.77 , and from adults was 0.66 . Therefore, as seen from the low-frequency attenuation evident in the four examples in Figure 1, the receptive field surround appears to be fully developed by 1 week of age and does not grow in relative strength during development, and may actually weaken slightly.

There was about a twofold increase in the mean characteristic spatial frequency between 4 weeks and 6 months of age across the population of P-cells (Fig. 2, $c$ vs $e$ ), indicating a corresponding reduction in receptive field center size. However, there was little change in the characteristic spatial frequency during the first 4 weeks of postnatal life (Fig. 2, $a$ vs $c$ ). In contrast to the P-cells, the $\mathrm{M}$-cell population showed a near-doubling in characteristic spatial frequency during the first 4 weeks postnatally (Fig. 2, $b$ vs $d$ ) and a very modest improvement later ( $d$ vs $f)$. Between the age of 1 week and adulthood, characteristic spatial frequency increased by a factor of 2-2.5 for both cell populations. Figure 2 suggests that this change might occur earlier in M-cells than P-cells. To test whether this difference in developmental rates was significant, we plotted the logarithm of characteristic spatial frequency for the two cell groups as a function of the logarithm of age, and fit the result with a second-order polynomial. Plotted in this way (see Fig. 10a), the curve for M-cells is convex, whereas that for $\mathrm{P}$-cells is concave. The coefficient of the square term in the fit was

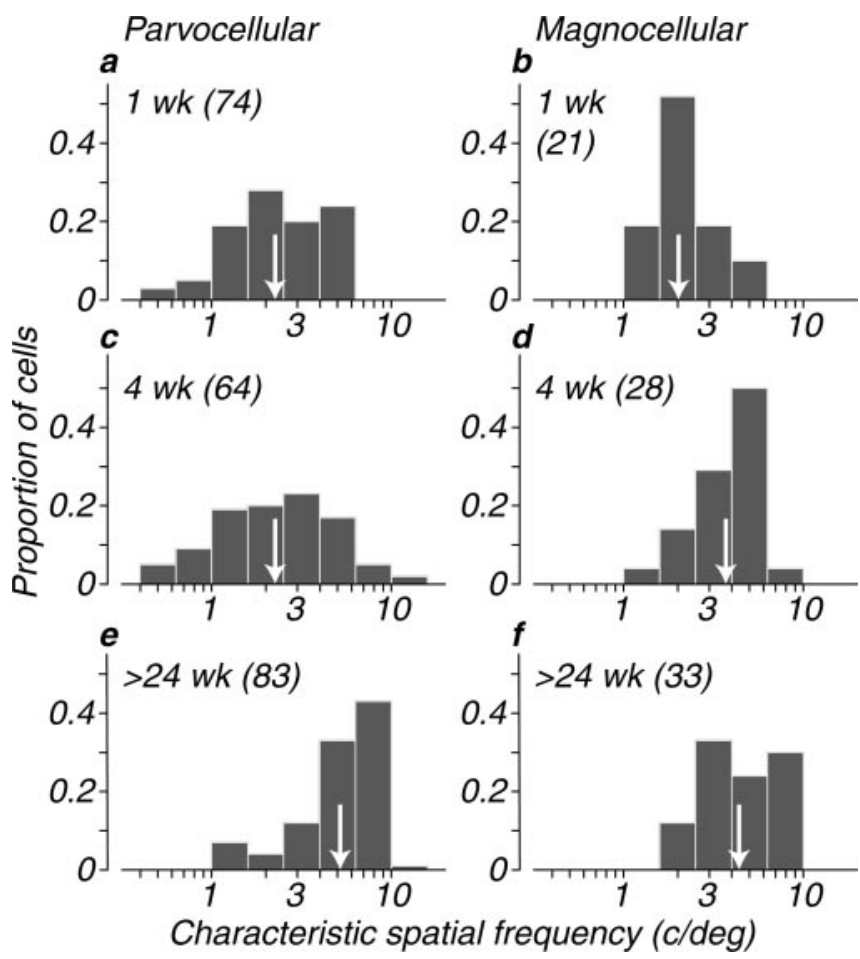

Figure 2. Distributions of characteristic spatial frequency across the population in the three age groups for parvocellular and magnocellular LGN neurons. A white arrow indicates the geometric mean of each distribution. $\boldsymbol{a}$ and $\boldsymbol{b}$ show the distributions for 1-week-old animals. $\boldsymbol{c}$ and $\boldsymbol{d}$ show the distributions for 4-week-old animals. $\boldsymbol{e}$ and $\boldsymbol{f}$ show the distributions for animals older than 24 weeks.

therefore positive for P-cells and negative for M-cells, and the $95 \%$ confidence intervals of the values of the two coefficients did not overlap. We conclude that the difference in developmental rates between $\mathrm{M}$ - and $\mathrm{P}$-cells is significant. 


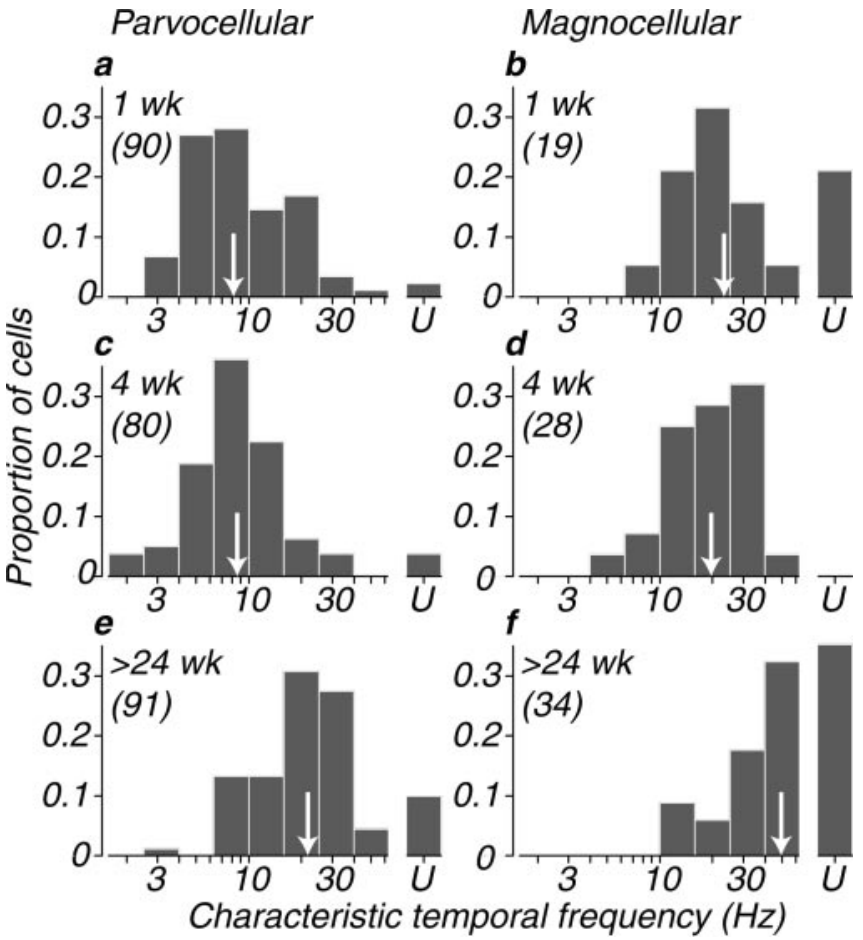

Figure 3. Distributions of characteristic temporal frequency across the population in the three age groups for parvocellular and magnocellular LGN neurons. Our measurements were limited to a maximum frequency of $26.7 \mathrm{~Hz}$, and we therefore did not estimate characteristic frequency values that were higher than twice that value; these values are represented by the bins labeled "U." A white arrow indicates the median of each distribution (the median is the appropriate measure of central tendency for these data because of the number of undefined values in the "U" bins). $\boldsymbol{a}$ and $\boldsymbol{b}$ show the distributions for 1 -week-old animals. $\boldsymbol{c}$ and $\boldsymbol{d}$ show the distributions for 4-week-old animals. $\boldsymbol{e}$ and $\boldsymbol{f}$ show the distributions for animals older than 24 weeks.

\section{Temporal properties}

We measured responses to a range of temporal frequencies with gratings of optimal spatial frequency. The overall shapes of the temporal tuning functions from the young animals were similar to those of the adults. Many showed mild-to-moderate low temporal frequency attenuation that did not appear to show major changes during maturation. Response functions for representative $\mathrm{M}$ - and P-cells from the 1-week-old and adult groups are shown in Figure $1 a-d$ (right panels); the characteristic temporal frequency for each cell is indicated by an arrow. The major change during development is in the range of high temporal frequencies to which neurons will respond. The tuning of the LGN P-cell from the 1 week old (Fig. $1 a$, right) showed a characteristic temporal frequency of $4.9 \mathrm{~Hz}$, more than two octaves lower than the value of $26.1 \mathrm{~Hz}$ for the adult example P-cell (Fig. 1b, right). The 1 week M-cell had a characteristic temporal frequency of 24.9 $\mathrm{Hz}$, much higher than that of the P-cell from the same 1 week old, yet an octave lower than the value of $50.6 \mathrm{~Hz}$ for the adult M-cell (Fig. 1d, right).

The trends that we observed in the example cells were also evident in the population. The median characteristic temporal frequency for the 1 week $\mathrm{P}$-cell population was $8.1 \mathrm{~Hz}$, compared with $8.7 \mathrm{~Hz}$ for the 4-week-old group and $22.0 \mathrm{~Hz}$ for the adult group (Fig. $3 a, c, e$ ). The M-cells showed a similar trend: the median characteristic temporal frequency for the 1 week population was $23.4 \mathrm{~Hz}$ compared with $19.8 \mathrm{~Hz}$ for the 4 week group and 49.7 $\mathrm{Hz}$ for the adult group (Fig. $3 b, d, f$ ).

We also studied a second measure of temporal processing,

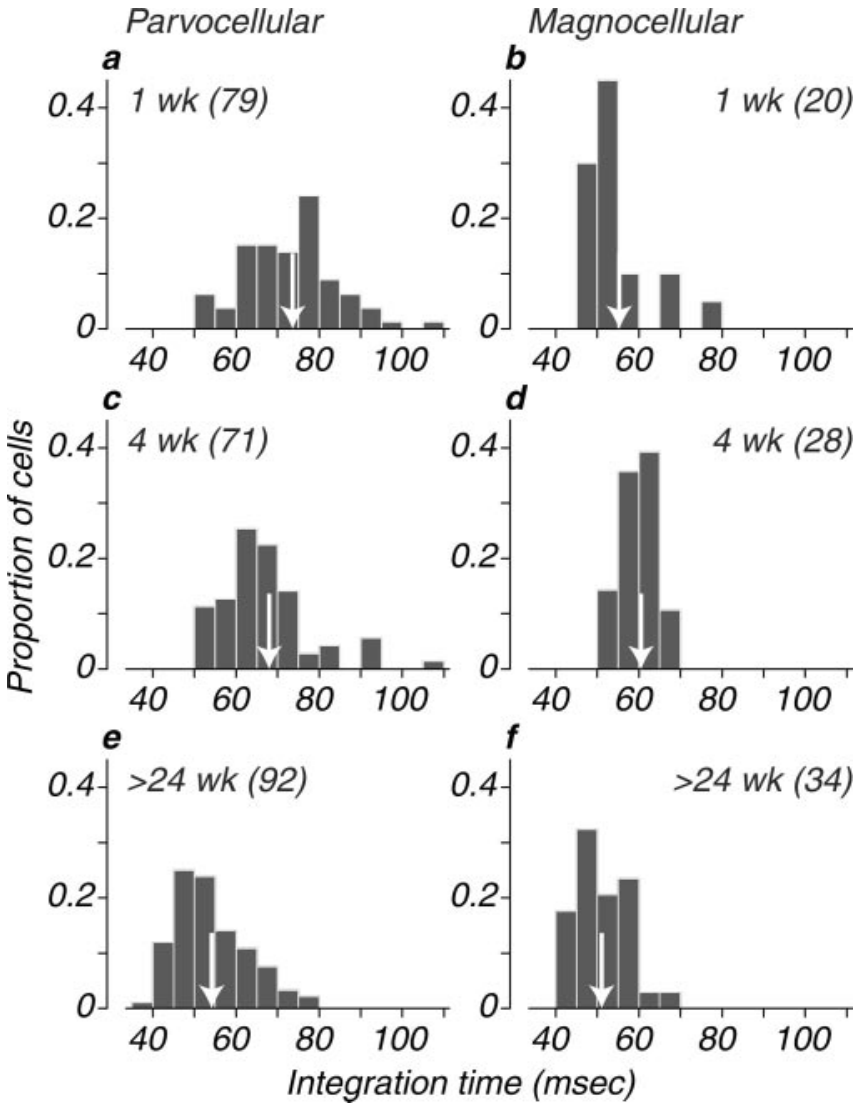

Figure 4. Distributions of integration time across the population in the three age groups for parvocellular and magnocellular LGN neurons. Integration time is the slope of the line relating response phase to temporal frequency (see Materials and Methods) (Eq. 3). Data are included only for cases in which the correlation between phase and frequency equaled or exceeded 0.8 . A white arrow indicates the mean of each distribution. $\boldsymbol{a}$ and $\boldsymbol{b}$ show the distributions for 1-week-old animals. $\boldsymbol{c}$ and $\boldsymbol{d}$ show the distributions for 4-week-old animals. $\boldsymbol{e}$ and $\boldsymbol{f}$ show the distributions for animals older than 24 weeks.

integration time, as a function of age. The integration time is a combination of the visual processing delays, synaptic integration delays, and conduction time (Reid et al., 1992). This measure is obtained from the slope of the phase versus temporal frequency plot (for details, see Materials and Methods). For the P-cell population, there was a progressive reduction in integration time with increasing postnatal age (Fig. $4 a, c, e$ ). The reduction in mean integration time is from $73.6 \mathrm{~ms}$ for the 1-week-old population of P-cells to $67.6 \mathrm{~ms}$ at 4 weeks and $54.3 \mathrm{~ms}$ for the adult P-cells. Integration times for the $\mathrm{M}$-cells changed little during development (Fig. $4 b, d, f$ ). The 1 -week-old M-cell population had a mean integration time of $55.1 \mathrm{~ms}$ compared with $60.4 \mathrm{~ms}$ at 4 weeks and $51.4 \mathrm{~ms}$ for the adult population.

Thus, the most obvious developmental change in temporal properties was the substantial increase in temporal resolution (as captured by the characteristic temporal frequency) between the ages of 4 and 24 weeks. The change in integration time during development was comparatively modest in P-cells, and not detectable at all in M-cells. If the development of temporal resolution reflected a simple change in the time scale of all of the neural processing, then temporal resolution and integration time should change together. A direct comparison of characteristic temporal frequency with integration time reveals a fairly consistent relationship between the two measures across different age groups and cell types (Fig. 5). However, the relationship is much shal- 


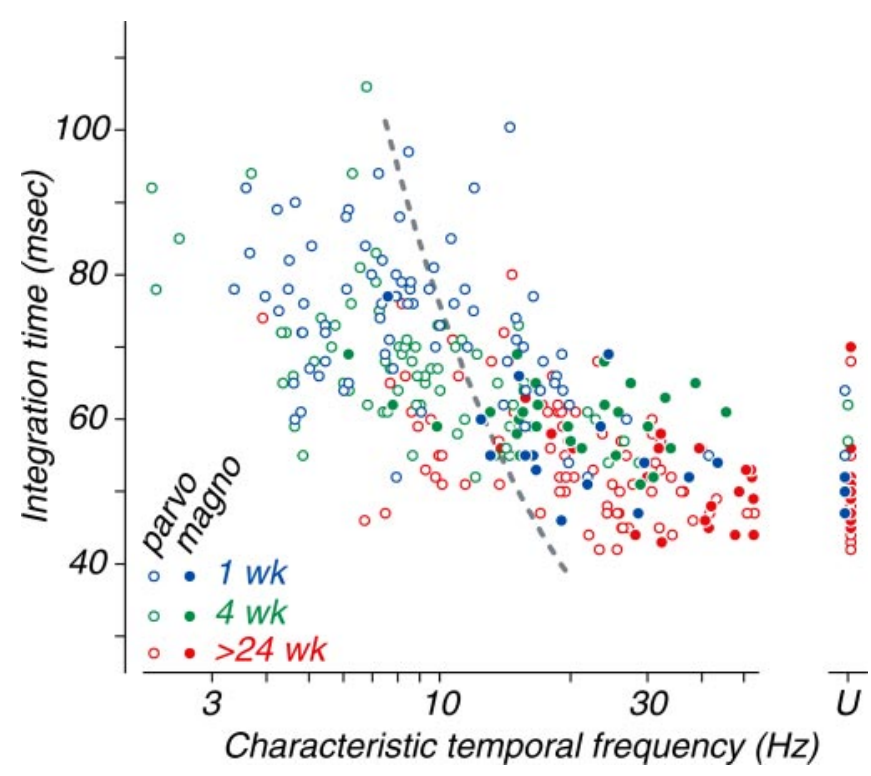

Figure 5. The relationship between integration time and characteristic temporal frequency for $\mathrm{M}$ - and $\mathrm{P}$-cells for all three age groups is shown. The two measures are, as expected, inversely related (slope of $-26.1 \mathrm{~ms}$ per decade) and strongly correlated ( $r=-0.65 ; n=292 ; p<$ 0.0001). Data for cells of all ages and types appear to fall along a single trend line, but this line is much shallower than would be expected if integration time and characteristic temporal frequency were inversely proportional (dashed gray curve). Twenty-nine cells, the characteristic temporal frequency of which was $>53 \mathrm{~Hz}$, are plotted at the point labeled " $U$ " and were excluded from the statistical analysis. parvo, Parvocellular; magno, magnocellular.

lower than would be predicted by the time-rescaling idea, indicated by the gray dashed line. This means that during development, a relatively fast processing speed (temporal integration time) does not mean that a cell will have the ability to follow fast stimulus modulation rates. There must be an additional factor that attenuates responses to high temporal frequencies under steady-state test conditions in young animals.

\section{Contrast sensitivity and responsivity}

One of the most noticeable changes in visual development is a dramatic improvement in behavioral contrast sensitivity over the first year of postnatal life (Boothe et al., 1988; Movshon and Kiorpes, 1988). We studied the development of sensitivity for each neuron by recording the response as a function of contrast for stimuli of the optimal spatial and temporal frequency. Figure 6 shows contrast response data from example M- and P-cells from a 1-week-old and an adult animal; these illustrate some of the main features of contrast response maturation. The left-hand curves in each panel of Figure 6 show phase-aligned contrast response functions (Levitt et al., 2001); the right-hand plots show response phase and amplitude for the same data.

Responsivity is the initial slope of the contrast response function (Hochstein and Shapley, 1976), and we used this measure to quantify contrast gain (Levitt et al., 2001). Our measure differs in one important respect from the one used in previous studies, for reasons that can be seen in Figure 6, $a$ and $c$. The usual function fit to contrast response data are constrained to pass through zero response at zero contrast. This is accurate and reasonable for LGN neurons in adults, because they almost all have spontaneous activity and the modulation of that activity by drifting gratings can be discerned for arbitrarily low contrasts if one averages for enough trials (cf. Enroth-Cugell and Robson, 1966). In infants, however, many cells have little or no spontaneous firing, and this makes it likely that they have a true threshold, in the same way that many cortical neurons do in adults (Movshon et al., 1978). Inspection of the response curves in Figure 6, $a$ and $c$, for 1 week data, reveals this threshold behavior. The dashed curves show the best fit of Equation 3 to these data with $b$ set to 0 (i.e., without a threshold). The solid curves show the fit when $b$ is allowed to take on negative values; they plainly provide a better account of the data. We therefore fit our population data in this way, and took the slope of the fitted function at the point at which it first exceeds 0 as our responsivity value. This technique allows us to compare the contrast gain for cells from animals of all ages, even those showing threshold behavior, although it discounts the effect of the threshold itself on neurons' signaling of very low stimulus contrasts.

The examples in Figure 6 represent the data from our population well. The 1 week cells, apart from the threshold just discussed, have contrast response functions that are similar to those of the adult cells in form and in slope. The P-cells both have effectively linear contrast response functions without evident saturation, whereas the M-cells both show the saturating nonlinearity characteristic of this cell type (Kaplan and Shapley, 1982).

Figure 7 shows distributions of responsivity for our population. In both infants and adults, the responsivity of the M-cell population was on average approximately seven times higher than for the P-cell population. Responsivity changed only slightly during development: the geometric mean responsivities for P-cells at 1, 4, and 24 weeks were 24.2, 27.0, and 33.8. For M-cells, the values were 129.4, 198.2, and 229.1. Even at the earliest stages of postnatal development, $\mathrm{M}$-cells are more responsive than the $\mathrm{P}$-cells to luminance-modulated stimuli, and their responsivity changes little with age. To determine sensitivity in a strict statistical sense, it is necessary to scale responses by their variability; we will present such an analysis in detail elsewhere, but for our purposes here, it is sufficient to know that contrast sensitivity is very closely related to responsivity for all ages and cell types.

It is important to recognize that our measure of responsivity, because it makes allowance for the threshold behavior observed in many infant neurons, does not necessarily directly reflect the response of neurons to very low contrasts. Rather, it is a measure of contrast gain that discounts the effect of threshold. The thresholds, estimated from the contrast at which the response function rises above zero (Fig. 6a,c), were statistically indistinguishable from 0 for all of the M-cells from the 4 week and adult groups, and for $76 \%$ of M-cells in the 1 week group. For P-cells, however, $41 \%$ of cells from 1 week animals, $65 \%$ of cells from 4 week animals, and $89 \%$ of cells from adult animals had thresholds of 0 . Thresholds for the remaining cells were $>0.1$ in $44 \%$ of 1 week P-cells, 32\% of 4 week P-cells, and 5\% of adult P-cells. Because these are hard thresholds, they will certainly limit the contribution made by high-threshold neurons to behavioral contrast sensitivity.

Another feature that distinguishes $\mathrm{M}$-cells from $\mathrm{P}$-cells in the adult retina and LGN is the degree to which they exhibit contrast gain control (Shapley and Victor, 1978; Benardete and Kaplan, 1999a,b; Levitt et al., 2001). For drifting grating stimuli, this gain control mechanism manifests itself as a phase advance with increasing levels of contrast in M-cells but not in P-cells. We measured the phase advance as a function of contrast in both $\mathrm{M}$ - and $\mathrm{P}$-cells at different ages. Phase-amplitude plots are shown in the right of each panel of Figure 6 for four example cells. The plots for both P-cells show little curvature, meaning that response phase did not change with contrast. The plots for both M-cells show considerable curvature, indicating that their response phase advanced with contrast (Benardete and Kaplan, 1999a; Levitt et al., 
a

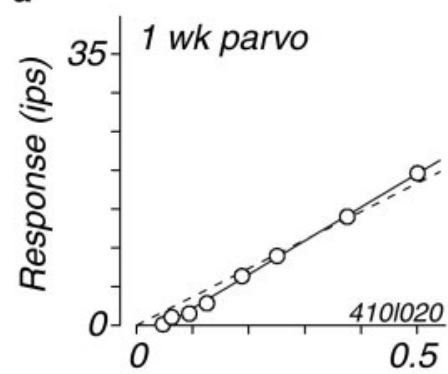

C

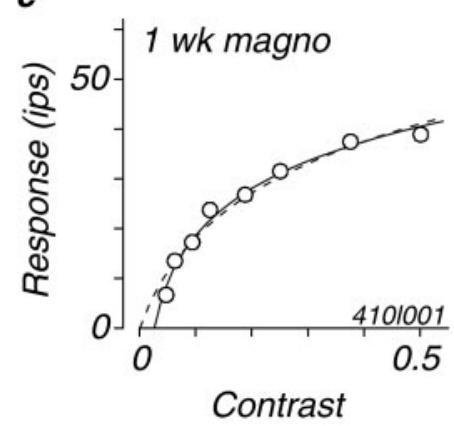

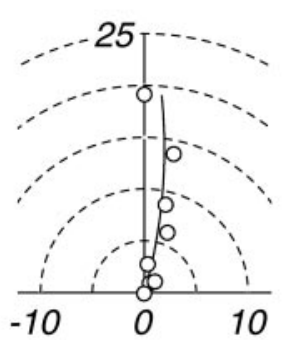

10

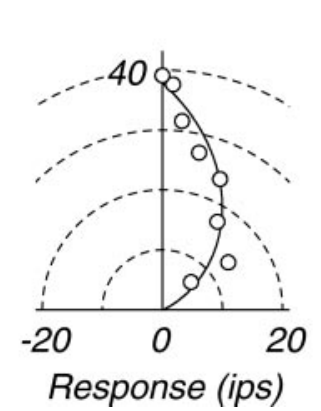

$\boldsymbol{b}$
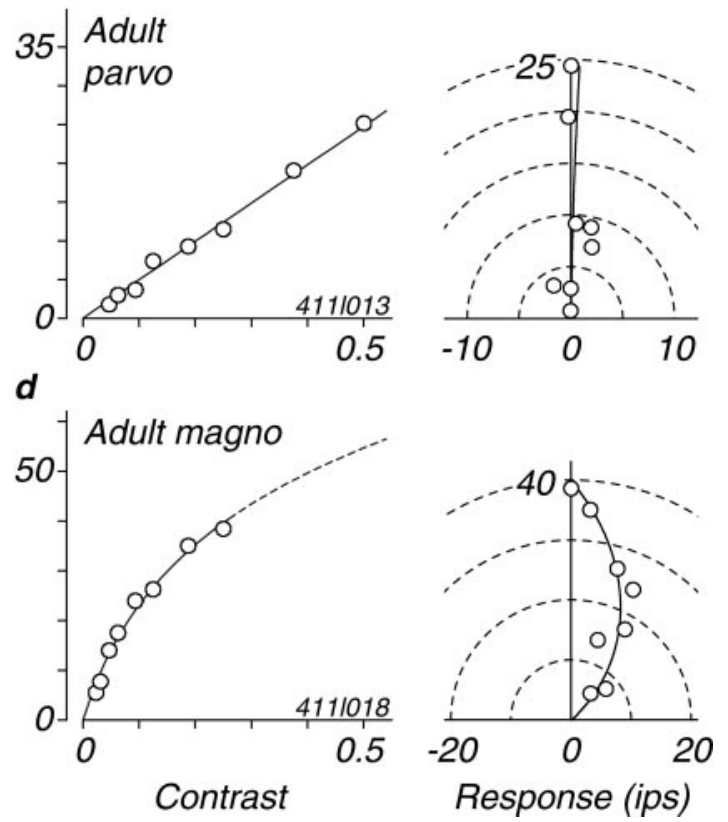

Figure 6. Examples of contrast responses from four $\mathrm{M}$ - and P-cells from 1-week-old infants and adults (these data are from the same example cells used for Fig. 1) are shown. The left side of each panel shows the phase-corrected response amplitude as a function of the contrast of an optimal grating. Solid curves are fits to the data from Equation 3 with the value of $b$ free to range $<0$. Dashed curves for the cells from 1 -week-old infants $(\boldsymbol{a}, \boldsymbol{c})$ show fits when the value of $b$ was fixed at 0 . The right side of each panel shows polar plots of the phase and amplitude of responses; phases are shifted so that the phase of the largest response is plotted at $90^{\circ}$ (i.e., on the ordinate). Smooth curves show fits of Equation 4 (see Materials and Methods). parvo, Parvocellular; magno, magnocellular.

2001). We computed a normalized measure of phase advance per unit contrast (see Materials and Methods), and the distribution of values for this measure is shown in Figure 8. P-cells showed a modest phase advance of 20-25 ms at all ages, whereas M-cells showed a much larger advance of 60-80 ms. The phase advance distribution for 4 week M-cells is shifted $\sim 20 \mathrm{~ms}$ compared to either 1 week or adult M-cells; the significance of this observation is uncertain.

Overall, most of the functional contrast response characteristics that distinguish $\mathrm{M}$ - and $\mathrm{P}$-cells are evident and qualitatively mature within a week after birth. The quantitative changes shown in Figures 7 and 8 seem quite modest compared with the striking behavioral changes evident over the same developmental period.

\section{Retinogeniculate information transfer}

The reliability of transmission between a retinal ganglion cell and its LGN recipient relay neuron can be characterized by measuring the relationship between S-potentials and LGN spikes (Kaplan and Shapley, 1984). In the adult, the transfer ratio is typically between 20 and 50\% depending on a number of factors including contrast and temporal frequency for both M- and P-cells (Kaplan et al., 1987). In addition to the transfer ratio, simultaneous S-potential and spike recordings can be used to analyze the precision in the transfer of signals from retina to LGN. In seven cases, we were able to record an unambiguous S-potential associated with an LGN cell spike. As is the case in adults, the two members of each pair always had similar visual response properties. Example data from a pair of P-cells from a 4-week-old animal are shown in Figure 9. Figure $9 a$ plots forward and reverse correlations between the S-potential and the associated LGN spike. The solid curve whose peak precedes zero is the time of the S-potential relative to each LGN spike. The peak time is $\sim 1.1 \mathrm{~ms}$, and the area under the peak is close to 1 , meaning that most LGN spikes were in this case preceded by an S-potential, suggesting potent one-to- one connectivity. The later peak (dashed curve) is for the LGN spikes relative to an S-potential at zero delay, and naturally also has a peak time of $1.1 \mathrm{~ms}$. For seven cells from 1 and 4 week olds, we measured times to peak between 0.5 and $1.6 \mathrm{~ms}$; the peak width ranged from 0.45 to $0.63 \mathrm{~ms}$. These values are well within the range found in adult LGN (Kaplan et al., 1987). Figure 9b shows example average response histograms for the units from the same pair recording, showing that the responses were inphase and similar in form as expected for a pair of cells with like receptive fields. The responses of the LGN cell (dark shading) were substantially weaker than those of the S-potential (light shading), and also seem more sharply rectified. This is even clearer from inspection of Figure $9 c$, which plots the firing rates of the two units, measured over $60 \mathrm{~ms}$ bins, against one another. The LGN cell fired almost no impulses when the firing rate of the S-potential was $<20$ ips; otherwise, the two rates are related with a slope of 0.33 , as indicated by the gray line, the best thresholdlinear fit to the data. As expected for such a correlated pair of units, the spatial and temporal frequency tuning characteristics were very similar (Fig. 9d), apart from the obviously higher firing rates of the S-potential. We were able to compare spatial frequency tuning for all seven pair recordings, and temporal frequency tuning for five of the seven. In no case did the tuning curves differ substantially except in magnitude; the values of the characteristic spatial and temporal frequencies usually agreed to within $40 \%$, and never differed by as much as a factor of 2 . Along with the precise temporal correlation shown in Figure $9 a$, these similarities indicate that the relay of signals from retina to LGN in infant animals is as precise as it is in adults. This suggests that immaturities evident in the LGN, especially in the time domain (Figs. 3-5), are not attributable to sloppy or unreliable transfer at the retinogeniculate synapse; rather, the retinal inputs themselves must have similarly limited temporal resolution. In the example pair of Figure 9, the transfer ratio, the probability that an LGN 


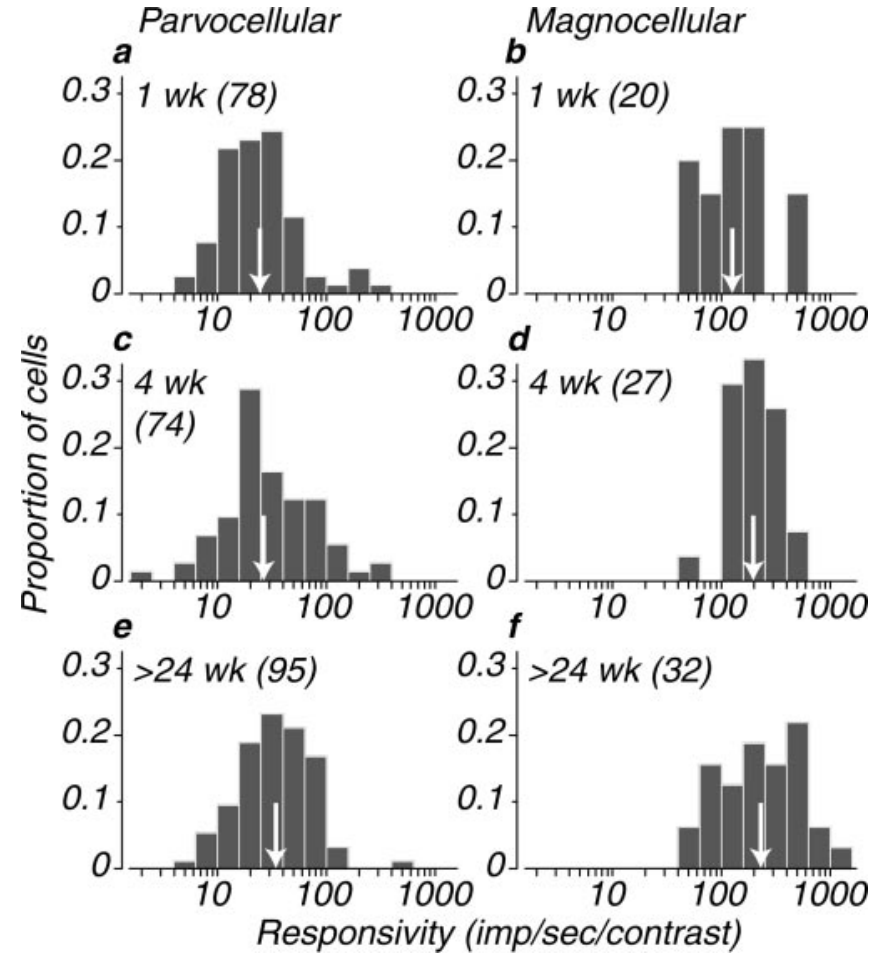

Figure 7. Distributions of responsivity across the population in the three age groups for parvocellular and magnocellular LGN neurons are shown. Responsivity is the slope of the line relating response to contrast at the point at which response first exceeds 0 (see Materials and Methods). A white arrow indicates the geometric mean of each distribution. $\boldsymbol{a}$ and $\boldsymbol{b}$ show the distributions for 1-week-old animals. $\boldsymbol{c}$ and $\boldsymbol{d}$ show the distributions for 4-week-old animals. $\boldsymbol{e}$ and $\boldsymbol{f}$ show the distributions for animals older than 24 weeks.

spike would follow an S-potential with short latency, was $26 \%$ (averaged across conditions). Transfer ratios for the seven cases were between 11 and 45\%, perhaps slightly lower than reported in adults by Kaplan et al. (1987).

\section{Discussion}

Our results reveal a consistent developmental pattern in the responses of macaque LGN neurons from the age of 1 week through adulthood. Spatial and temporal resolution improve by a factor of $2-3$, whereas contrast responses increase by a factor of $\sim 1.5$ 1.8. All of the main organizational features of adult LGN receptive fields are also evident in infant neurons, including the spatially antagonistic receptive field surround, and the distinctive features of contrast response and contrast gain control that distinguish $\mathrm{M}$ - and P-cells. The maturational changes we observed were less extensive than those reported by Blakemore and VitalDurand (1986) and by Hawken et al. (1997). We wondered whether the difference might be attributable to the larger and more consistent sample of cells we were able to study quantitatively, but direct comparisons suggest that there is a genuine difference in the data sets obtained from the youngest infants, in which we consistently found higher spatial resolution and better contrast response than the previous studies. Visual processing in the LGN is therefore substantially more mature than had been thought. It follows that there is relatively little room for later improvement, and the changes we observed in spatial resolution and contrast response are therefore modest when compared with behavioral changes measured over the same time period.

Figure 10 compares our data with behavioral and theoretical measurements of spatial resolution and contrast sensitivity. Each

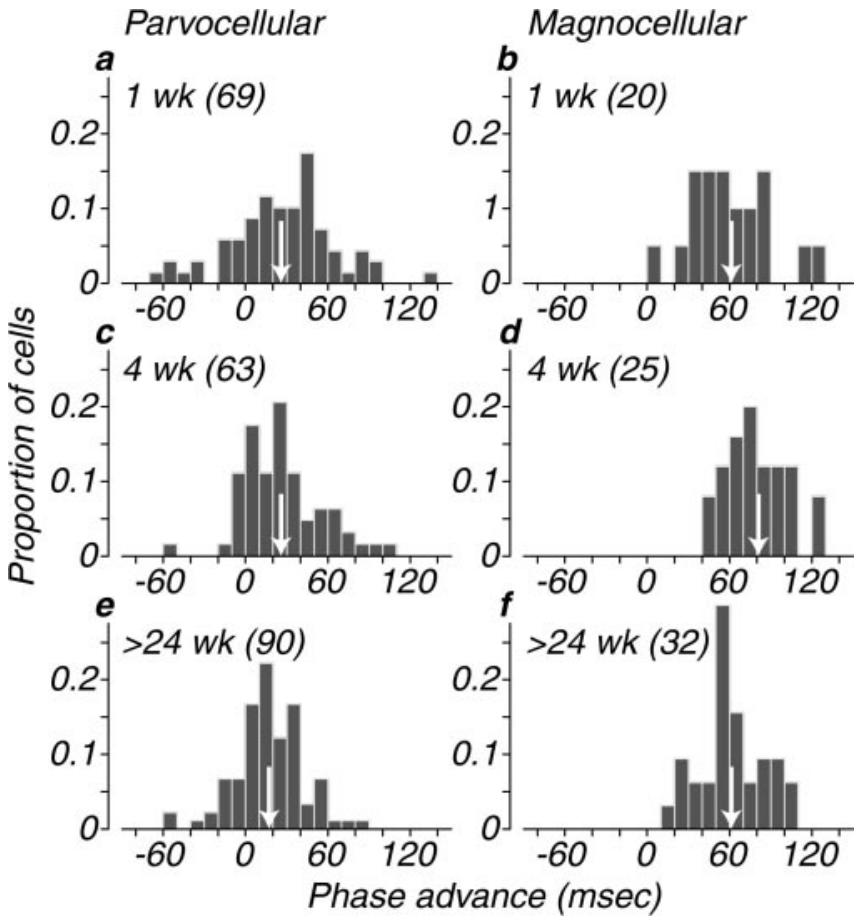

Figure 8. Distributions of phase advance across the population in the three age groups for parvocellular and magnocellular LGN neurons are shown. Phase advance is the shift in response phase between contrasts of 0 and 1, computed as a time shift in milliseconds using Equation 5 (see Materials and Methods). A white arrow indicates the geometric mean of each distribution. $\boldsymbol{a}$ and $\boldsymbol{b}$ show the distributions for 1-week-old animals. $\boldsymbol{c}$ and $\boldsymbol{d}$ show the distributions for 4-week-old animals. $\boldsymbol{e}$ and $\boldsymbol{f}$ show the distributions for animals older than 24 weeks.

panel shows developmental progressions for related sets of parameters, normalized to values of 1 for adults. This normalization facilitates comparison of the developmental rates for the different measures, and does not mean that the values are all equal or equivalent. Figure $10 a$ shows a comparison of spatial resolution development. As shown in Figure 2, M- and P-cell populations shift their spatial tuning toward higher frequencies during development (the data used in Fig. 10 are only from neurons with receptive fields within $6^{\circ}$ of the fovea). The inverse of our measure of spatial resolution, characteristic spatial frequency, estimates the size of the center of the receptive field (Enroth-Cugell and Robson, 1966; Linsenmeier et al., 1982), and changes in characteristic frequency are therefore inversely proportional to changes in receptive field center size. Such changes could arise by a reorganization of the receptor inputs to retinal ganglion cells, or by refinement of the convergence of ganglion cells to LGN cells (Chen and Regehr, 2000), but we favor a simpler explanation: cones in the infant retina are not tightly clustered in the fovea, and migrate toward the center of gaze over the first postnatal year to find their adult positions (Packer et al., 1990). Moreover, the eye grows significantly over the same period, increasing the magnification of the retinal image (Blakemore and Vital-Durand, 1986; Kiorpes et al., 2003). These two factors combine to change the Nyquist frequency (or intercone spacing) of the foveal cone mosaic by a factor of 3 from 1 week to adulthood (Fig. 10a, large open circles). If we suppose that cones retain their central connections as they migrate, then much of the change in receptive field center size implied by the changes in characteristic spatial frequency could be due simply to changes in retinal and eye morphology (Wilson, 1988, 1993). The magnitude of the changes we observed (Fig. 10a) is fractionally smaller than predicted by this 

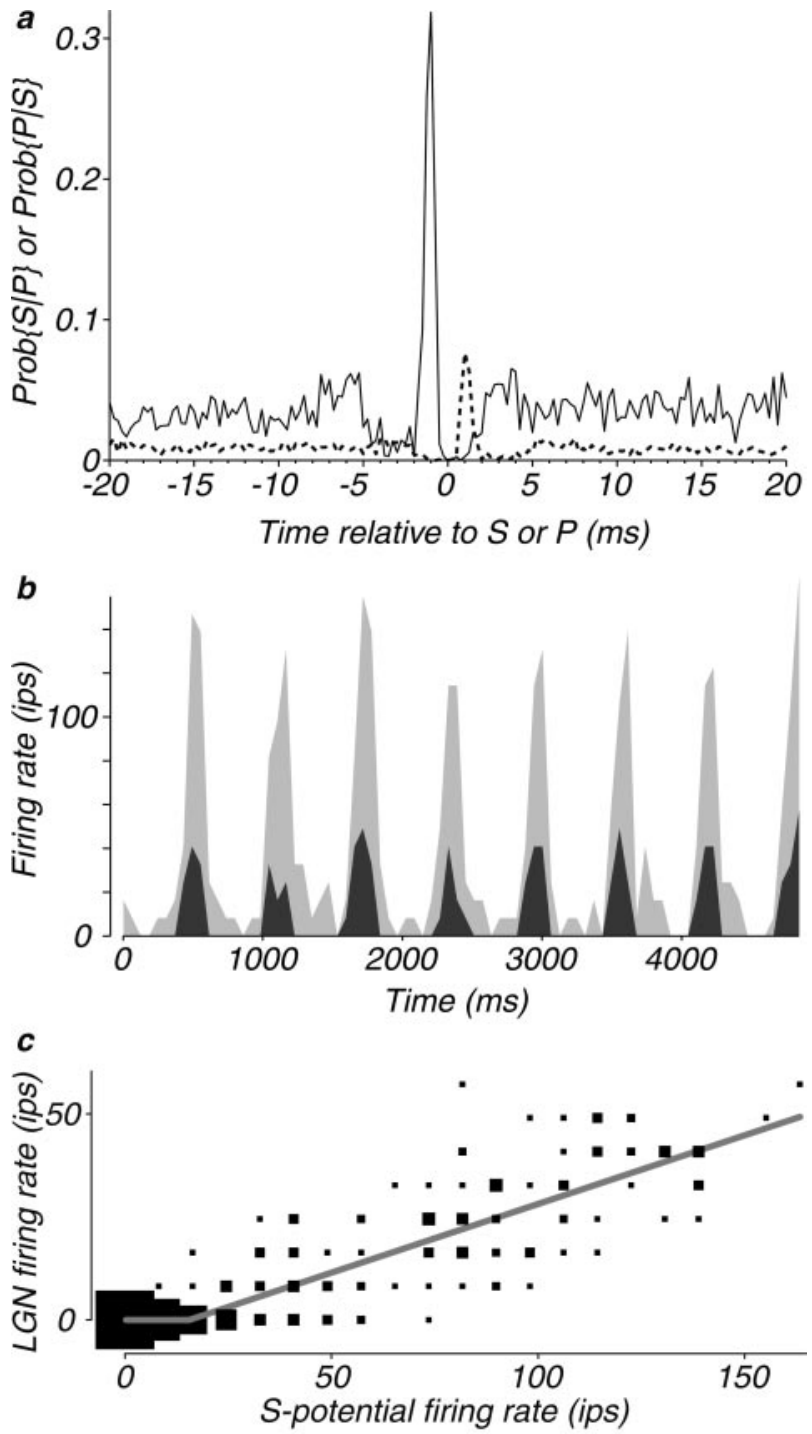

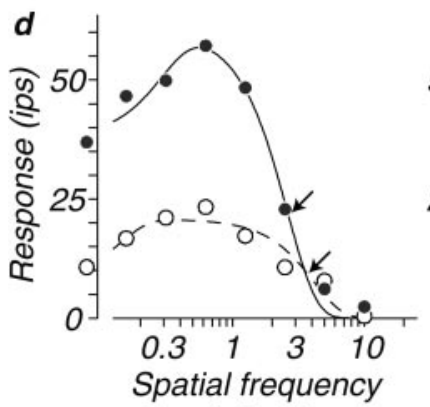

(c/deg)

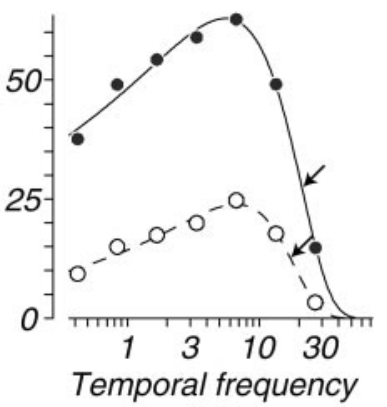

$(\mathrm{Hz})$
Figure 9. An example of the temporal correlation of LGN cell extracellularly recorded action potentials (S) and the synaptic prepotential (S-potential) recorded on the same electrode (P) is shown. $\boldsymbol{a}$ The solid line represents the probability (Prob) that an S-potential occurred in each $0.25 \mathrm{~ms}$ time bin relative to an LGN cell action potential at time 0 . The dashed line shows the probability that an LGN-cell action potential was found in each $0.25 \mathrm{~ms}$ time bin relative to an $\mathrm{S}$-potential at time $0 . \boldsymbol{b}$, Response histograms showing the averaged response of both units to a grating of $0.6 \mathrm{c} / \mathrm{deg}$ drifting at $1.7 \mathrm{~Hz}$ The dark shading is for the LGN cell, and the light shading is for the S-potential. c, A scatter histogram showing the relationship between the firing rates of the S-potential and the LGN cell for a set of representative conditions (spatial frequency, $0.6 \mathrm{c} / \mathrm{deg}$; temporal frequencies, $0.4-3.3 \mathrm{~Hz}$ ). The area of each square represents the proportion of $60 \mathrm{~ms}$ bins in which the joint firing rates of the units were as indicated; the large square at $(0,0)$ corresponds to $33 \%$ of cases. The gray line is the best thresholdlinear fit to the data; its $x$-intercept is $13.8 \mathrm{ips}$, and its slope is 0.33 . $\mathbf{d}$, Spatial and temporal frequency tuning for the same unit pair. The tuning curves in each domain are similar, as are the values of characteristic spatial and temporal frequency (arrows, as in Fig. 1).

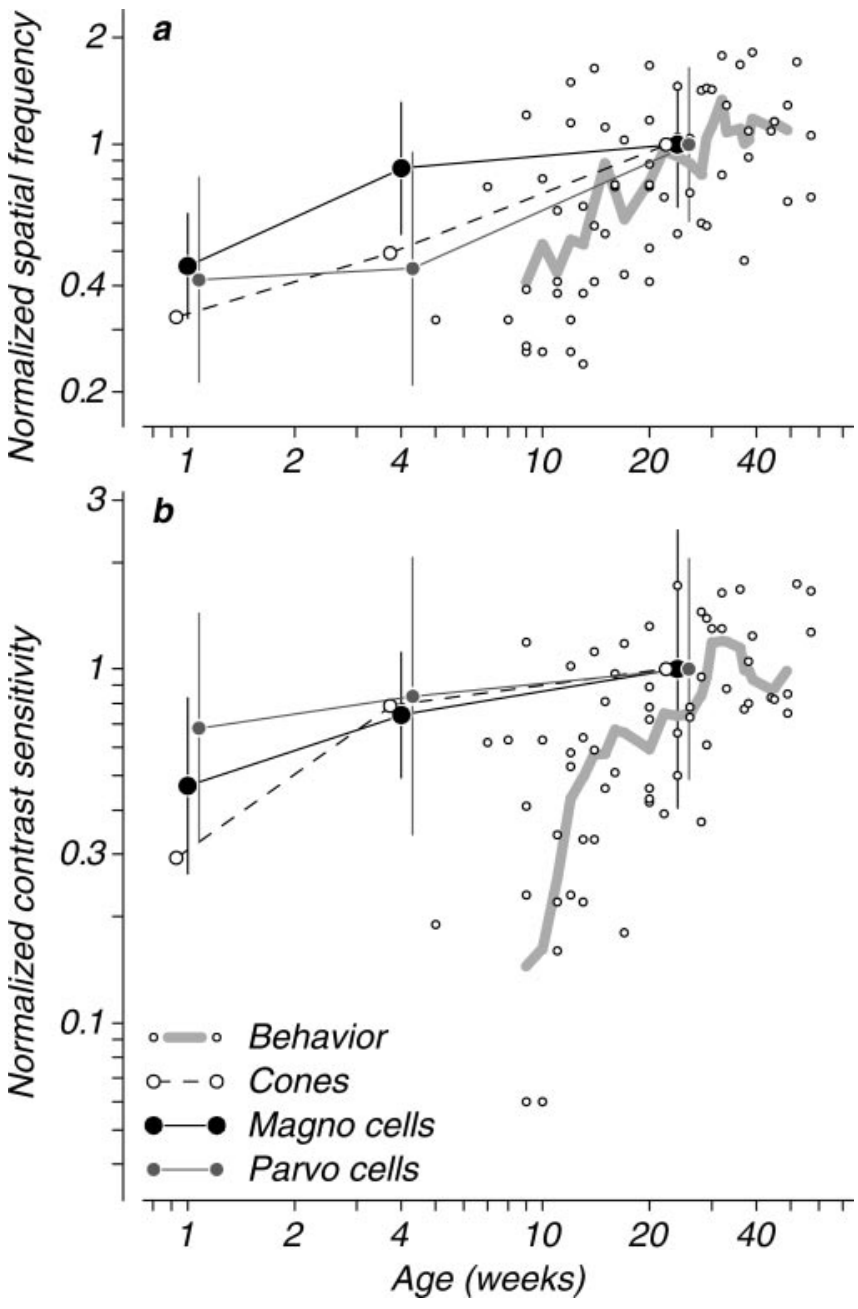

Figure 10. Comparisons of the development of spatial resolution and contrast sensitivity for LGN cells, behavior, and the retinal cone mosaic. LGN data (filled symbols) are from the present study; data are included only for cells whose receptive fields lay within $6^{\circ}$ of the fovea. Each point represents the geometric mean, and error bars indicate \pm 1 SD. Behavioral data (small open circles) are from Boothe et al. (1988); points indicate individual observations, and the light gray lines represent the running means of eight adjacent observations. Retinal data (open circles) are from the ideal observer analysis of Kiorpes et al. (2003) and represent measurements of the retinas of the four youngest monkeys and of one of the adult controls from the present study. All of the values are normalized to 1 at the adult point ( 24 wk or older) to facilitate comparison of developmental rates. $\boldsymbol{a}$, Development of spatial resolution. LGN data are the characteristic spatial frequencies (Fig. 2), behavioral data are the spatial frequencies at the peak of the contrast sensitivity function, and cone data are the Nyquist limits (inverse of minimum intercone spacing) for the array of foveal cones. $\boldsymbol{b}$, Development of contrast response. LGN data are the responsivities (Fig. 7), behavioral data are the peak values of contrast sensitivity, and cone data are the predicted contrast sensitivities of average individual foveal cones based on analysis of their light-capturing properties taken from their morphology. parvo, Parvocellular; magno, magnocellular.

model, perhaps because many of our receptive fields were not in the central fovea where cone density changes are measured. In addition, the maturation of $\mathrm{M}$-cell spatial properties is significantly faster than for P-cells, an effect for which cone migration offers no obvious explanation. It is also evident from Figure $10 a$ that, on average (gray line), behavioral changes in peak spatial frequency (small circles) occur much later and are greater in magnitude than the neural changes we measured and modeled. We conclude that these behavioral changes are attributable to limits set later in the visual system.

Figure $10 b$ shows a similar analysis of contrast response, in- 
cluding our LGN cell populations, ideal observer predictions, and behavioral data. In this case also, the behavioral changes happen much later and are much more extensive that those in LGN cells and in cone sensitivity. It might seem puzzling that the responsivity of our LGN cells changed less over development than the sensitivity — predicted by an ideal observer model—of the cones that drive them. This may be because the ideal observer's performance is limited only by photon noise, whereas the performance of real observers and neurons is also limited by other, neural sources of noise (Kiorpes et al., 2003). It is also worth noting that the effects of the high firing threshold (Figs. 6, 9) on the responsivity of infant neurons, especially P-cells, is not captured by the responsivity values plotted in Figure 10b; these values may therefore overestimate the behaviorally relevant contrast sensitivity of infant P-cells.

What limits the development of temporal sensitivity? The largest developmental changes we observed were in temporal resolution, and the poor response of many infant LGN cells to high temporal frequency stimuli was very obvious. The ideal observer model makes no predictions for temporal sensitivity (Kiorpes et al., 2003), and behavioral data on the development of temporal contrast sensitivity in infant monkeys are not available. The apparently paradoxical difference between the extensive development of temporal resolution (Fig. 3), and the more modest improvement in integration time (Figs. 4, 5), also calls for explanation. One account for this behavior might be changes in the depression properties of synapses in infants. Chance et al. (1998) showed in a theoretical study that short-term synaptic depression can act as a nonlinear low-pass filter. Such a filter leaves transient responses relatively unaffected (and would therefore permit short integration times), but selectively attenuates responses to steady-state stimuli of high frequency. There is evidence for changes in short-term synaptic depression of the right kind to produce our effects in developing spinal cord (Li and Burke, 2002). It is unclear where in the developing macaque visual system this depression might be manifest. Our data on S-potentials, although limited, suggest that the retinal input to LGN has poor temporal resolution and in fact sets the limit on LGN resolution (Fig. 9). This early temporal limit seems to be set in the retina, so we speculate that the limits arise from abnormally profound depression of retinal synapses rather than in the phototransduction process itself. This is also consistent with the pattern of development of human retinal temporal sensitivity measured with the ERG (Westall et al., 1999).

In summary, the maturational changes in the visual signals relayed by LGN cells might be attributable to a few simple factors. The change in spatial receptive field structure might simply reflect the migration of cones toward the fovea. Changes in temporal resolution and contrast response might result from changes in peripheral synaptic function and also in the changes in excitability implied by the low spontaneous activity seen in infant neurons. Although these modest changes might somehow have a disproportionate influence on downstream neurons in visual cortex, it seems more likely that maturational changes in the LGN are of limited consequence for visual development. The limits on infant visual performance, then, lie downstream of the LGN, in the visual areas of the cortex.

\section{References}

Banks MS, Bennett PJ (1988) Optical and photoreceptor immaturities limit the spatial and chromatic vision of human neonates. J Opt Soc Am A 5:2059-2079.

Banks MS, Crowell J (1993) Front end limitations to infant spatial vision: examination of two analyses. In: Early visual development: normal and abnormal (Simons K, ed), pp 91-116. New York: Oxford UP.

Benardete EA, Kaplan E (1999a) The dynamics of primate M retinal ganglion cells. Vis Neurosci 16:355-368.

Benardete EA, Kaplan E (1999b) Dynamics of primate P retinal ganglion cells: responses to chromatic and achromatic stimuli. J Physiol (Lond) 519:775-790.

Blakemore C, Vital-Durand F (1986) Organization and post-natal development of the monkey's lateral geniculate nucleus. J Physiol (Lond) 380:453-491.

Boothe RG, Kiorpes L, Williams RA, Teller DY (1988) Operant measurements of contrast sensitivity in infant macaque monkeys during normal development. Vision Res 28:387-396.

Brown AM (1993) Intrinsic noise and infant visual performance. In: Early visual development: normal and abnormal (Simons K, ed), pp 178-198. New York: Oxford UP.

Brown AM, Dobson V, Maier J (1987) Visual acuity of human infants at scotopic, mesopic and photopic luminances. Vision Res 27:1845-1858.

Chance FS, Nelson SB, Abbott LF (1998) Synaptic depression and the temporal response characteristics of V1 cells. J Neurosci 18:4785-4799.

Chen C, Regehr WG (2000) Developmental remodeling of the retinogeniculate synapse. Neuron 28:955-966.

Ellemberg D, Lewis TL, Maurer D, Liu CH, Brent HP (1999) Development of spatial and temporal vision during childhood. Vision Res 39:2325-2333.

Enroth-Cugell C, Robson JG (1966) The contrast sensitivity of retinal ganglion cells of the cat. J Physiol (Lond) 187:517-552.

Hawken MJ, Blakemore C, Morley JW (1997) Development of contrast sensitivity and temporal-frequency selectivity in primate lateral geniculate. Exp Brain Res 114:86-98.

Hendrickson AE (1992) A morphological comparison of foveal development in man and monkey. Eye 6:136-144.

Hendry SH, Reid RC (2000) The koniocellular pathway in primate vision. Annu Rev Neurosci 23:127-153.

Hochstein S, Shapley RM (1976) Linear and nonlinear spatial subunits in Y cat retinal ganglion cells. J Physiol (Lond) 262:265-284.

Kaplan E, Shapley RM (1982) X and Y cells in the lateral geniculate nucleus of macaque monkeys. J Physiol (Lond) 330:125-143.

Kaplan E, Shapley RM (1984) The origin of the S (slow) potential in the mammalian lateral geniculate nucleus. Exp Brain Res 55:111-116.

Kaplan E, Purpura K, Shapley RM (1987) Contrast affects the transmission of visual information through the mammalian lateral geniculate nucleus. J Physiol (Lond) 391:267-288.

Kiorpes L (1992) Development of vernier acuity and grating acuity in normally reared monkeys. Vis Neurosci 9:243-251.

Kiorpes L, Kiper DC (1996) Development of contrast sensitivity across the visual field in macaque monkeys (Macaca nemestrina). Vision Res 36:239-247.

Kiorpes L, Movshon JA (1998) Peripheral and central factors limiting the development of contrast sensitivity in macaque monkeys. Vision Res 38:61-70.

Kiorpes L, Movshon JA (2004) Neural limitations on visual development in primates. In: The visual neurosciences (Chalupa L, Werner JS, eds), pp 159-173. Cambridge, MA: MIT.

Kiorpes L, Tang C, Hawken MJ, Movshon JA (2003) Ideal observer analysis of the development of spatial contrast sensitivity in macaque monkeys. J Vis 3:630-641.

Levitt JB, Schumer RA, Sherman SM, Spear PD, Movshon JA (2001) Visual response properties of neurons in the LGN of normally reared and visually deprived macaque monkeys. J Neurophysiol 85:2111-2123.

Li Y, Burke RE (2002) Developmental changes in short-term synaptic depression in the neonatal mouse spinal cord. J Neurophysiol 88:3218-3231.

Linsenmeier RA, Frishman LJ, Jakiela HG, Enroth-Cugell C (1982) Receptive field properties of $\mathrm{X}$ and $\mathrm{Y}$ cells in the cat retina derived from contrast sensitivity measurements. Vision Res 22:1173-1183.

Malpeli JG, Baker FH (1975) The representation of the visual field in the lateral geniculate nucleus of Macaca mulatta. J Comp Neurol 161:569-594.

Malpeli JG, Lee D, Baker FH (1996) Laminar and retinotopic organization of the macaque lateral geniculate nucleus: magnocellular and parvocellular magnification functions. J Comp Neurol 375:363-377. 
Mayer DL, Dobson V (1982) Visual acuity development in infants and young children, as assessed by operant preferential looking. Vision Res 22:1141-1151.

Merrill EG, Ainsworth A (1972) Glass-coated platinum-plated tungsten microelectrode. Med Biol Eng 10:495-504.

Mitchell DE, Giffin F, Wilkinson F, Anderson P, Smith ML (1976) Visual resolution in young kittens. Vision Res 16:363-366.

Movshon JA, Kiorpes L (1988) Analysis of the development of spatial contrast sensitivity in monkey and human infants. J Opt Soc Am A 5:2166-2172.

Movshon JA, Thompson ID, Tolhurst DJ (1978) Spatial summation in the receptive fields of simple cells in the cat's striate cortex. J Physiol (Lond) 283:53-77.

Packer O, Hendrickson AE, Curcio CA (1990) Developmental redistribution of photoreceptors across the Macaca nemestrina (pigtail macaque) retina. J Comp Neurol 298:472-493.
Reid RC, Victor JD, Shapley RM (1992) Broadband temporal stimuli decrease the integration time of neurons in cat striate cortex. Vis Neurosci 9:39-45.

Rusoff AC, Dubin MW (1977) Development of receptive-field properties of retinal ganglion cells in kittens. J Neurophysiol 40:1188-1198.

Shapley RM, Victor JD (1978) The effect of contrast on the transfer properties of cat retinal ganglion cells. J Physiol (Lond) 285:275-298.

Wässle H, Boycott BB (1991) Functional architecture of the mammalian retina. Physiol Rev 71:447-480.

Westall CA, Panton CM, Levi AV (1999) Time course for maturation of electroretinogram responses from infancy to adulthood. Doc Ophthalmol 93:355-379.

Wilson HR (1988) Development of spatiotemporal mechanisms in infant vision. Vision Res 28:611-628.

Wilson HR (1993) Theories of infant visual development. In: Early visual development: normal and abnormal (Simons K, ed), pp 560-572. New York: Oxford UP. 